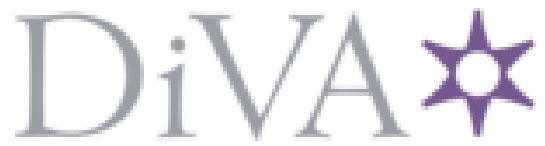

http://www.diva-portal.org

This is the published version of a paper published in Journal of Chemical Physics.

Citation for the original published paper (version of record):

Brumboiu, I E., Ericsson, L K., Hansson, R., Moons, E., Eriksson, O. et al. (2015)

The influence of oxygen adsorption on the NEXAFS and core-level XPS spectra of the C6o derivative PCBM.

Journal of Chemical Physics, 142: 054306

https://doi.org/10.1063/1.4907012

Access to the published version may require subscription.

N.B. When citing this work, cite the original published paper.

Permanent link to this version:

http://urn.kb.se/resolve?urn=urn:nbn:se:kau:diva-35419 


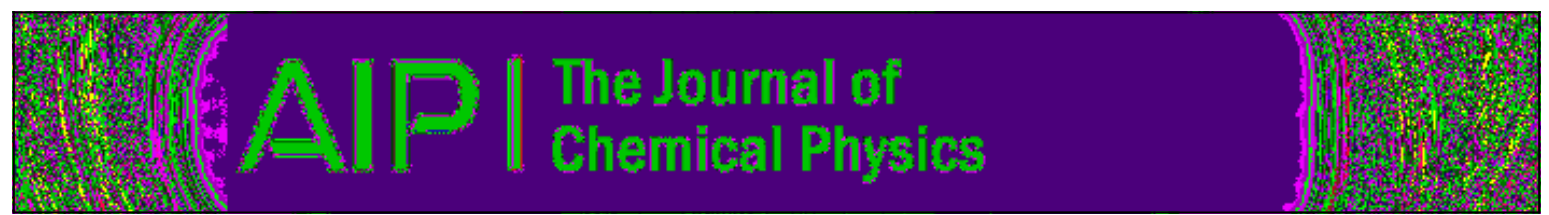

\section{The influence of oxygen adsorption on the NEXAFS and core-level XPS spectra of the $\mathbf{C 6 0}$ derivative PCBM}

Iulia Emilia Brumboiu, Leif Ericsson, Rickard Hansson, Ellen Moons, Olle Eriksson, and Barbara Brena

Citation: The Journal of Chemical Physics 142, 054306 (2015); doi: 10.1063/1.4907012

View online: http://dx.doi.org/10.1063/1.4907012

View Table of Contents: http://scitation.aip.org/content/aip/journal/jcp/142/5?ver=pdfcov

Published by the AIP Publishing

\section{Articles you may be interested in}

Vibrationally resolved high-resolution NEXAFS and XPS spectra of phenanthrene and coronene

J. Chem. Phys. 141, 044313 (2014); 10.1063/1.4891221

A comparative theoretical study on core-hole excitation spectra of azafullerene and its derivatives

J. Chem. Phys. 140, 124304 (2014); 10.1063/1.4868717

Investigating the molecule-substrate interaction of prototypic tetrapyrrole compounds: Adsorption and selfmetalation of porphine on $\mathrm{Cu}(111)$

J. Chem. Phys. 138, 154710 (2013); 10.1063/1.4800771

Adsorption geometry and core excitation spectra of three phenylpropene isomers on $\mathrm{Cu}(111)$

J. Chem. Phys. 125, 034701 (2006); 10.1063/1.2212398

Comment on "In situ X-ray photoelectron spectroscopic and density-functional studies of Si atoms adsorbed on a C 60 film" [J. Chem. Phys.121, 11351 (2004)]

J. Chem. Phys. 122, 237101 (2005); 10.1063/1.1929735

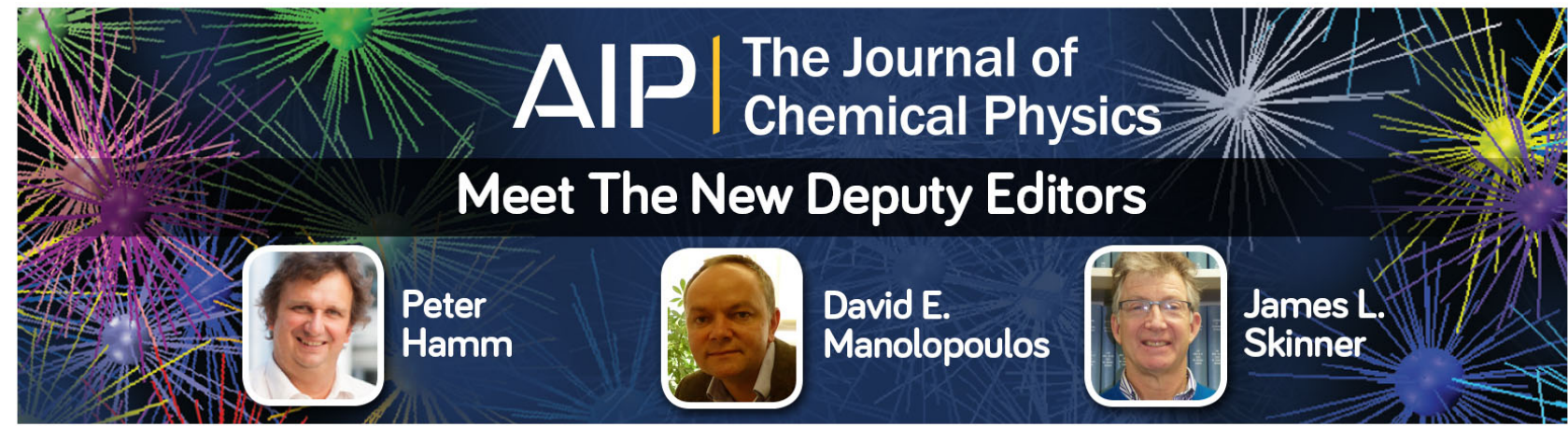




\title{
The influence of oxygen adsorption on the NEXAFS and core-level XPS spectra of the $\mathrm{C}_{60}$ derivative PCBM
}

\author{
Iulia Emilia Brumboiu, ${ }^{1, a)}$ Leif Ericsson, ${ }^{2}$ Rickard Hansson, ${ }^{2}$ Ellen Moons, ${ }^{2}$ Olle Eriksson, ${ }^{1}$ \\ and Barbara Brena ${ }^{1}$ \\ ${ }^{1}$ Department of Physics and Astronomy, Uppsala University, SE-75120 Uppsala, Sweden \\ ${ }^{2}$ Department of Engineering and Physics, Karlstad University, SE-65188 Karlstad, Sweden
}

(Received 21 October 2014; accepted 14 January 2015; published online 4 February 2015)

Fullerenes have been a main focus of scientific research since their discovery due to the interesting possible applications in various fields like organic photovoltaics (OPVs). In particular, the derivative [6,6]-phenyl- $\mathrm{C}_{60}$-butyric acid methyl ester (PCBM) is currently one of the most popular choices due to its higher solubility in organic solvents compared to unsubstituted $\mathrm{C}_{60}$. One of the central issues in the field of OPVs is device stability, since modules undergo deterioration (losses in efficiency, open circuit voltage, and short circuit current) during operation. In the case of fullerenes, several possibilities have been proposed, including dimerization, oxidation, and impurity related deterioration. We have studied by means of density functional theory the possibility of oxygen adsorption on the $\mathrm{C}_{60}$ molecular moiety of PCBM. The aim is to provide guidelines for near edge X-ray absorption fine structure (NEXAFS) and X-ray photoelectron spectroscopy (XPS) measurements which can probe the presence of atomic or molecular oxygen on the fullerene cage. By analysing several configurations of PCBM with one or more adsorbed oxygen atoms, we show that a joint core level XPS and O1s NEXAFS investigation could be effectively used not only to confirm oxygen adsorption but also to pinpoint the bonding configuration and the nature of the adsorbate. (C) 2015 AIP Publishing LLC. [http://dx.doi.org/10.1063/1.4907012]

\section{INTRODUCTION}

Organic photovoltaics (OPV) are becoming a viable alternative to other emerging technologies, especially by offering the possibility of large-scale production of regular as well as novel flexible devices. The materials employed can be easily deposited onto plastic substrates by techniques such as the roll-to-roll printing which encompasses a low production cost and low environmental impact. ${ }^{1,2}$

In recent years, the record power conversion efficiencies (PCE) achieved by single junction OPVs have surpassed $8 \%,{ }^{3}$ with most of the devices reaching up to $4 \%-5 \%$ PCE. $^{2}$ Moreover, modules with 5\% PCE show a short energy payback time (EPBT) and high energy return factors (ERF) ${ }^{2,4}$ which, alongside the fast processability, make polymer solar cells competitive with technologies currently on the market. ${ }^{2}$ However, one very important problem that still needs to be solved before this type of devices becomes effective is their stability.

The active layer of an OPV consists of a donor-acceptor blend. There are a large number of organic polymers that can be used as electron donors but so far the class of electronacceptor materials has been limited to fullerenes, with one particular $\mathrm{C}_{60}$ derivative, the phenyl-[6,6]- $\mathrm{C}_{60}$-methyl-ester (PCBM), as the most widely used in actual devices. ${ }^{5,6}$ It has been shown by numerous studies that OPVs, as well as their organic constituents separately, undergo deterioration during

\footnotetext{
a)Electronic mail: iulia.brumboiu@physics.uu.se
}

device operation ${ }^{7-13}$ (a good review of stability issues in polymer photovoltaics is Ref. 13).

Several studies have focused on the deterioration of either the polymer:fullerene blend or the fullerene derivative separately. In the specific case of PCBM, Reese et al., ${ }^{9}$ by performing mobility measurements in combination with matrix assisted laser desorption/ionization time of flight mass spectroscopy (MALDI-TOF) of P3HT:PCBM blends exposed to light in air, suggested as a possible deterioration mechanism the chemisorption of atomic oxygen to the $\mathrm{C}_{60}$ cage. On the contrary, Bao et al. ${ }^{14}$ by core level and valence band $\mathrm{x}$ ray photoelectron spectroscopy (XPS) observe no chemical bonding between oxygen and the $\mathrm{C}_{60}$ cage of PCBM molecules exposed to an $\mathrm{O}_{2}$ atmosphere.

As shown by Volonakis et al. ${ }^{15}$ in a theoretical study of the PCBM crystal, the presence of oxygen can create new states in the band gap which act as traps and recombination centres reducing charge mobility and thus the OPV's efficiency. In this study, we have focused on the interaction of atomic and molecular oxygen with the single PCBM molecule and have investigated by means of density functional theory (DFT) the influence of oxygen adsorption on the O1s XPS and near-edge $\mathrm{x}$-ray absorption fine structure (NEXAFS) spectra. The aim is to offer guidelines for X-ray spectroscopy experiments which can probe oxygen adsorption to the molecule. We show that by a joint O1s XPS and NEXAFS investigation, it is possible to determine not only if either atomic or molecular oxygen is attached to the cage but also the configuration in which the atoms are adsorbed, forming an epoxide (the oxygen across two neighbouring hexagons, denoted here as a 6-6 
configuration) or an open isomer (the $\mathrm{O}$ across a pentagon and hexagon: 5-6 configuration). Our study is relevant not only for photovoltaics but also in the field of fullerene chemistry, since the combination of O1s XPS and NEXAFS can be used to indicate which PCBM-O isomer is formed under a particular reaction.

\section{COMPUTATIONAL METHODS}

The geometry of several configurations of PCBM with one or two oxygen atoms adsorbed on the fullerene cage (Fig. 1) was optimized using the B3LYP functional ${ }^{16}$ in combination with the $6-31 \mathrm{G}(\mathrm{d}, \mathrm{p})$ basis set $^{17}$ implemented in the Gaussian 09 quantum chemistry software. ${ }^{18}$ The optimized geometry was then used to determine the O1s NEXAFS spectra by calculating the transition probabilities from oxygen $1 \mathrm{~s}$ orbitals to unoccupied molecular levels. These transition matrix elements were calculated by means of the gradientcorrected DFT software $\mathrm{StoBe}^{19}$ in the dipole approximation using the exchange functional by Becke ${ }^{20}$ and the correlation functional by Perdew. ${ }^{21}$ The transition potential method which assumes that the core excited level is half occupied was used to account for relaxation effects. ${ }^{22,23}$ A single NEXFAS spectrum was obtained for each oxygen atom in the molecule. Each spectrum was shifted to the Kohn-Sham ionization potential $\left(\mathrm{IP}_{\mathrm{KS}}\right)$ calculated as the difference between the total energy of the molecule in presence of a core hole on the specific atom and the ground state energy. The $\mathrm{IP}_{\mathrm{KS}}$ was used in addition to construct the core level XPS spectra. After the shift, the single-atom NEXAFS spectrum was broadened using a gaussian function of variable full width half maximum (fwhm) as performed in our previous study. ${ }^{24}$ The total spectrum was obtained by averaging the signal of the component atoms. In the case of the XPS spectra, a gaussian broadening with a constant full width half maximum of $1.0 \mathrm{eV}$ was performed in order to simulate the spectrometer resolution and to facilitate the comparison to experiment. The total core level XPS was obtained by summing up the single-atom spectra. Both XPS and NEXAFS spectra were shifted in order to match the experimental first peak. All the XPS spectra were shifted by $5.2 \mathrm{eV}$ towards lower binding energies, while the NEXAFS spectra were shifted by $0.6 \mathrm{eV}$

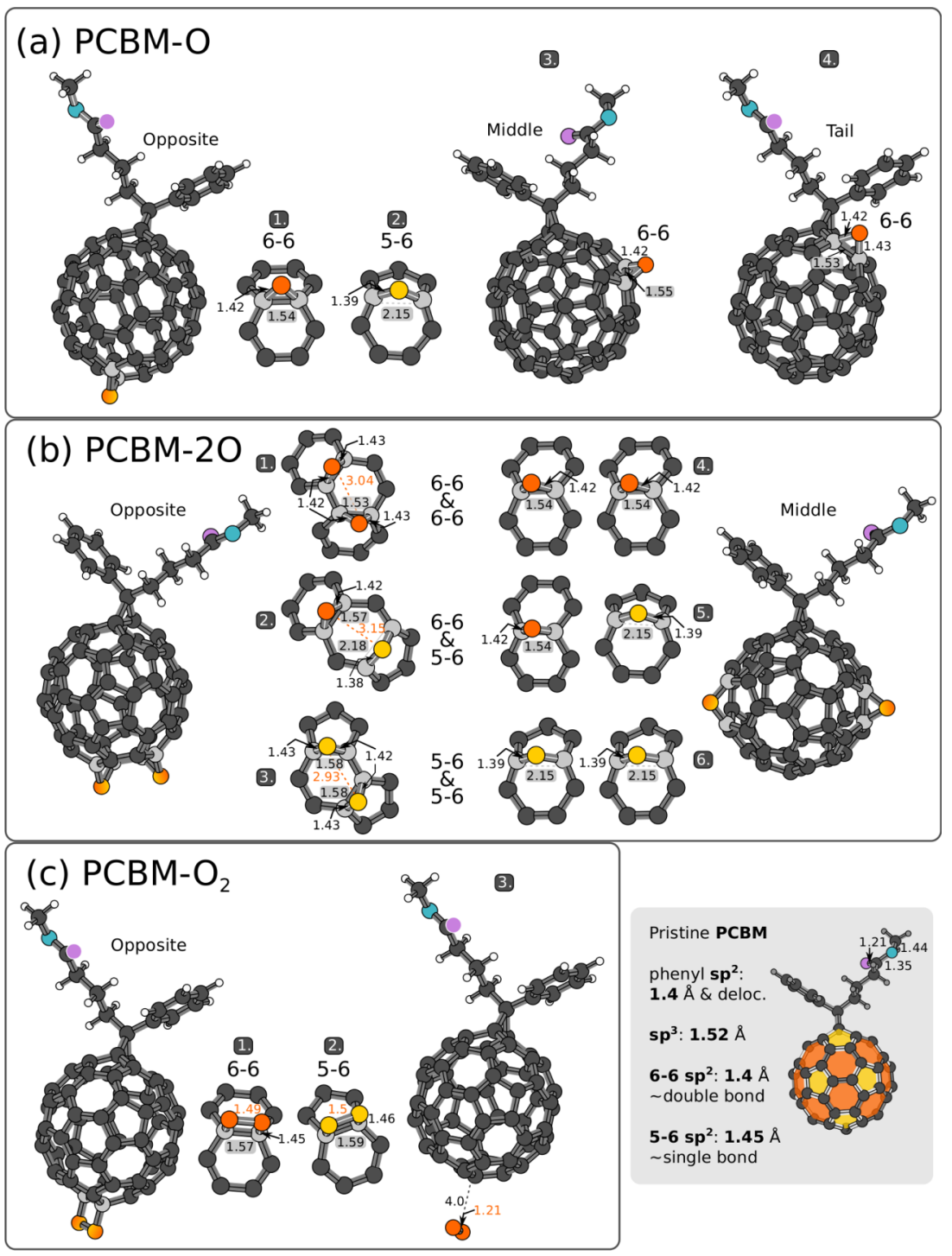

FIG. 1. Optimized geometries of PCBM with one adsorbed oxygen atom (a), with 2 oxygen atoms (b), and with an adsorbed oxygen molecule (c). C atoms are depicted in grey, pristine-PCBM $\mathrm{O}$ atoms are depicted in blue $(\mathrm{C}-\mathrm{O}-\mathrm{C})$ and purple $(\mathrm{O}=\mathrm{C})$, while the additional $\mathrm{O}$ atoms are either orange (6-6 configuration) or yellow (5-6 adsorption site). The inset contains the average bond lengths in pristine PCBM alongside a representation of the molecule. In the inset, $\mathrm{C}-\mathrm{C}$ bonds across two hexagons (double bonds) are dark grey, while bonds across a pentagon and a hexagon (single bonds) are light grey. 
towards higher photon energies. The shift of $0.6 \mathrm{eV}$ in the case of the NEXAFS spectrum accounts for relativistic effects (mass velocity and Darwin term). ${ }^{25}$

Figure 1 depicts the optimized geometries of the PCBM with oxygen configurations that were analysed. Before describing each of them, it is important to enumerate a few structural properties of the fullerene cage. The $C_{60}$ molecular moiety of PCBM consists of 60 carbon atoms disposed in 20 hexagons and 12 pentagons. The atoms in the cage are approximately $\mathrm{sp}^{2}$ hybridized with the exception of the two carbons at the attachment point which form $4 \sigma$ bonds and present therefore $\mathrm{sp}^{3}$ character. ${ }^{26}$ As demonstrated by several different experimental and theoretical studies, ${ }^{27-34}$ the bonds across two hexagons (6-6) are shorter than the bonds across a pentagon and a hexagon (5-6). Therefore, the most stable Kekulé structure of $\mathrm{C}_{60}$ consists of alternating double bonds at the junction between hexagons and single bonds at the pentagon-hexagon junctions. ${ }^{26,35}$ According to our calculations, in the pristine PCBM molecule, the 6-6 bonds are shorter by approximatively $0.05 \AA$ than the 5-6 bonds. This is in line with a series of experimental measurements performed on the $\mathrm{C}_{60}$ fullerene which obtained differences in bond length of approximately $0.05 \AA-0.10 \AA^{31-34}$ between the two types of bonds, with the 6-6 ones longer.

When it comes to oxygen adsorption, three distinct cases have been analysed: (a) 4 configurations with one chemisorbed oxygen atom (PCBM-O, Fig. 1(a)), (b) 6 configurations involving two chemisorbed atoms (PCBM-2O, Fig. 1(b)), and (c) 3 configurations where the undissociated $\mathrm{O}_{2}$ molecule was either chemisorbed or placed in the vicinity of the fullerene cage $\left(\mathrm{PCBM}-\mathrm{O}_{2}\right.$, Fig. 1(c)). The adsorption was performed on a 6-6 site (across two hexagons - Fig. 1 a1, a3, a4, b1, $\mathrm{b} 4$, and $\mathrm{c} 1$ ), on a 5-6 site (across a pentagon and a hexagon Fig. 1 a2, b3, b6, and c2), or on a combination of both (Fig. 1 b2 and b5). The atoms were placed either on the opposite side, in the middle of the cage, or close to the side-chain. In the case of the $\mathrm{O}_{2}$ molecule placed $4 \AA$ away from the $\mathrm{C}_{60}$ molecular moiety, both the singlet and the triplet electronic configurations for the oxygen were analysed. For the triplet state, separate calculations were performed for the spin up (majority $-\alpha$ ) and spin down (minority - $\beta$ ) electrons with the total spectrum being obtained as the sum (XPS) or weighted sum (NEXAFS) of the single atom components as described above.

The structures were compared to each other from the point of view of their relative binding energies, geometries, and lowest unoccupied molecular orbital (LUMO) position. The relative binding energy per oxygen atom, $\left(E_{R}\right)$, was defined as

$$
\begin{gathered}
E_{R}=E_{P C B M}+\frac{1}{2} E_{O_{2}}-E_{P C B M-O}, \\
E_{R}=\frac{1}{2}\left(E_{P C B M}+E_{O_{2}}-E_{P C B M-2 O}\right), \\
E_{R}=\frac{1}{2}\left(E_{P C B M}+E_{O_{2}}-E_{P C B M-O_{2}}\right),
\end{gathered}
$$

where $E_{P C B M}$ is the calculated ground state energy of the pristine molecule; $E_{O_{2}}$ is the ground state energy of an oxygen molecule in the triplet state; and $E_{P C B M-O}, E_{P C B M-2 O}$, and
$E_{P C B M-O_{2}}$ are the calculated energies of the PCBM with the adsorbed oxygen. $E_{R}$ represents the energy difference between the system (PCBM with adsorbed oxygen) and its isolated parts (PCBM, $\mathrm{O}_{2}$ ) normalized to the number of adsorbed atoms.

Zero-point corrections were also performed and the corresponding corrected relative binding energies $\left(E_{Z P C}\right)$ were calculated using the same equations (Eqs. (1)-(3)).

The particular structures (Table I) were chosen in order to shed light on the influence of adsorption site, placement on the cage, and the nature of the adsorbate (atomic or molecular oxygen) on the O1s XPS and NEXAFS spectra.

\section{EXPERIMENTAL METHODS}

Thin films of PCBM were prepared by spin-coating from a PCBM (99.5\%, Solenne BV, The Netherlands) solution in chloroform with a concentration of $12 \mathrm{mg} / \mathrm{ml}$. The spincoating was performed in protected atmosphere in a glove-box under yellow light with a spin speed of $3000 \mathrm{rpm}$ during $60 \mathrm{~s}$. Prior to spin-coating, the solutions, prepared in glove-box, were heated over night at $60{ }^{\circ} \mathrm{C}$. The substrates were n-type $\operatorname{Si}\left(\begin{array}{lll}0 & 0 & 1\end{array}\right)$ with a resistivity of $0.001-0.003 \Omega \mathrm{cm}$ that were cleaned according to the standard RCA method without the final HF-etching step. ${ }^{36-38}$ The films were protected from ambient light and air until measurement by using a custom built transfer box to the UHV system.

NEXAFS measurements were done at beam-line D1011 of the MAX-lab National Laboratory for Synchrotron Radiation in Lund, Sweden. Total electron yield spectra (TEY) were obtained by collecting the sample drain current. The spectra were measured at the magic angle, $55^{\circ}$ incidence relative to the sample surface. The spectra were divided by the corresponding spectrum of a freshly in situ Ar-sputtered $\mathrm{Au} / \mathrm{Mica}$ sample and then normalized in the high photon energy region according to the "Stable monitor method." 39,40

The XPS measurements were performed using the same equipment as for NEXAFS with the difference that the photoelectrons were collected with a VG Scienta SES200 analyser in the sample normal direction. The binding energy scale in XPS spectra was referenced to the Fermi level, as

\begin{tabular}{|c|c|c|c|c|}
\hline \multirow[b]{2}{*}{ Name } & \multirow[b]{2}{*}{ Adsorbate } & \multicolumn{3}{|c|}{ Placement } \\
\hline & & Opposite & Middle & Tail \\
\hline PCBM-O & $1 \mathrm{O}$ atom & $\begin{array}{l}6-6 \\
5-6\end{array}$ & $6-6$ & $6-6$ \\
\hline PCBM-2O & $2 \mathrm{O}$ atoms & $\begin{array}{l}6-6 \text {-6 } \\
6-65-6 \\
5-65-6\end{array}$ & $\begin{array}{l}6-6 \quad 6-6 \\
6-65-6 \\
5-65-6\end{array}$ & \\
\hline $\mathrm{PCBM}^{-\mathrm{O}_{2}}$ & $\mathrm{O}_{2}$ molecule & $\begin{array}{c}\text { 6-6 } \\
5-6 \\
\text { at } 4 \AA^{1} \mathrm{O}_{2} \\
\text { at } 4 \AA^{3} \mathrm{O}_{2}\end{array}$ & & \\
\hline
\end{tabular}
measured on a freshly in situ Ar-sputtered Au/Mica sample.

TABLE I. Overview of the studied structures. 
TABLE II. Relative binding energies per oxygen atom $\left(E_{R}\right)$, zero-point corrected relative energies $\left(E_{Z P C}\right)$, and LUMO position for all the studied PCBM-O structures.

\begin{tabular}{|c|c|c|c|c|}
\hline Adsorbate & $\begin{array}{l}\text { Placement and } \\
\text { adsorption site }\end{array}$ & $\mathrm{E}_{\mathrm{R}}(\mathrm{eV})$ & $\mathrm{E}_{\mathrm{ZPC}}(\mathrm{eV})$ & LUMO (eV) \\
\hline None & Pristine PCBM & $\ldots$ & $\ldots$ & -3.091 \\
\hline \multirow{4}{*}{$1 \mathrm{O}$ atom } & Opposite 6-6 & 0.59 & 0.55 & -3.19 \\
\hline & Opposite 5-6 & 0.68 & 0.65 & -3.14 \\
\hline & Middle 6-6 & 0.53 & 0.49 & -3.12 \\
\hline & Tail 6-6 & 0.68 & 0.63 & -3.19 \\
\hline \multirow{6}{*}{$2 \mathrm{O}$ atoms } & Opposite 6-6 6-6 & 0.69 & 0.65 & -3.27 \\
\hline & Opposite 6-6 5-6 & 0.74 & 0.70 & -3.22 \\
\hline & Opposite 5-6 5-6 & 0.23 & 0.21 & -3.29 \\
\hline & Middle 6-6 6-6 & 0.61 & 0.57 & -3.22 \\
\hline & Middle 6-6 5-6 & 0.65 & 0.61 & -3.17 \\
\hline & Middle 5-6 5-6 & 0.67 & 0.64 & -3.22 \\
\hline \multirow{4}{*}{$\mathrm{O}_{2}$ molecule } & Opposite 6-6 & -0.05 & -0.09 & -3.27 \\
\hline & Opposite $5-6$ & -0.47 & -0.50 & -3.71 \\
\hline & Opposite at $4 \AA^{1} \mathrm{O}_{2}$ & -1.85 & -0.85 & -4.76 \\
\hline & Opposite at $4 \AA^{3} \mathrm{O}_{2}$ & 0.002 & 0.001 & -3.093 \\
\hline
\end{tabular}

The spectra intensity was normalized to photon flux and a Shirley background was removed.

\section{RESULTS}

In the following, we present a thorough characterization of the calculated results for the three cases of PCBM with adsorbed oxygen (PCBM-O, PCBM-2O, and PCBM- $\mathrm{O}_{2}$ ). In the first section, all the optimized structures are described and compared, while the last two sections treat, case by case, the calculated O1s XPS and NEXAFS spectra.

\section{A. Optimized geometries}

\section{PCBM-O}

The optimized structures of PCBM with one $\mathrm{O}$ atom adsorbed to the fullerene cage are represented in Figure 1(a), alongside the most relevant bond lengths. The corresponding electronic properties, including the binding energies, are displayed in the first section of Table II. The bond lengths at the adsorption site are given in Table III. From a structural point of view, the three epoxide isomers (6-6 adsorption site, Fig. 1 a1, a3, and a4) are similar. The $\mathrm{C}-\mathrm{O}$ bond is in all cases $1.42 \AA$, while the $\mathrm{C}-\mathrm{C}$ bond at the adsorption site is stretched to approximately $1.54 \AA$ for all three structures (Table III). This value suggests that the $\pi$ bond across two hexagonal faces in pristine PCBM (1.4 $\AA$ ) breaks and the atoms remain connected only by a $\sigma$ bond.

In contrast, the adsorption of an oxygen atom on a 5-6 site (open isomer) affects the cage structure more strongly and results in completely breaking the single bond at the pentagon-hexagon junction. The two carbon atoms involved are pushed to approximately $2.15 \AA$ away from each other and the $\mathrm{C}-\mathrm{O}$ bond is shorter by $0.3 \AA$, as compared to the 6-6 case.

Energetically, the open isomer is predicted to have a higher relative binding energy by $0.09 \mathrm{eV}$ (Table II) than

TABLE III. C-C, C-O bond lengths at the adsorption site for the analysed PCBM-O structures.

\begin{tabular}{lllcc}
\hline \hline Adsorbate & Placement and site & Figure & $\mathrm{C}-\mathrm{C}(\AA)$ & $\mathrm{C}-\mathrm{O}(\AA)$ \\
\hline \multirow{4}{*}{$1 \mathrm{O}$ atom } & Opposite 6-6 & $1 \mathrm{a} 1$ & 1.54 & 1.42 \\
& Opposite 5-6 & $1 \mathrm{a} 2$ & 2.15 & 1.39 \\
& Middle 6-6 & $1 \mathrm{a} 3$ & 1.55 & 1.42 \\
& Tail 6-6 & $1 \mathrm{a} 4$ & 1.53 & 1.425 \\
& Opposite 6-6 6-6 & $1 \mathrm{~b} 1$ & 1.531 .53 & 1.4251 .425 \\
& Opposite 6-6 5-6 & $1 \mathrm{~b} 2$ & 1.572 .18 & 1.421 .38 \\
& Opposite 5-6 5-6 & $1 \mathrm{~b} 3$ & 1.581 .58 & 1.4251 .425 \\
& Middle 6-6 6-6 & $1 \mathrm{~b} 4$ & 1.541 .54 & 1.421 .42 \\
& Middle 6-6 5-6 & $1 \mathrm{~b} 5$ & 1.542 .15 & 1.421 .39 \\
& Middle 5-6 5-6 & $1 \mathrm{~b} 6$ & 2.152 .15 & 1.391 .39 \\
& Opposite 6-6 & $1 \mathrm{c} 1$ & 1.57 & 1.45 \\
$\mathrm{O}_{2}$ molecule & Opposite 5-6 & $1 \mathrm{c} 2$ & 1.59 & 1.46 \\
& At $4 \AA^{1} \mathrm{O}_{2}$ & $1 \mathrm{c} 3$ & Pristine & 4.0 (unoptimized) \\
& At 4 ${ }^{3} \mathrm{O}_{2}$ & $1 \mathrm{c} 3$ & Pristine & 4.0 (unoptimized) \\
\hline \hline
\end{tabular}


(a) PCBM-20

$5-6 \& 5-6$

Before

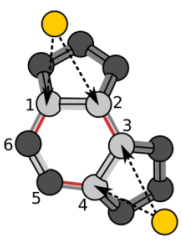

After

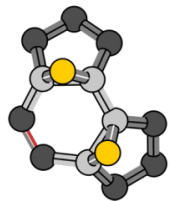

(b) $\mathrm{PCBM}-\mathrm{O}_{2}$ $5-6$
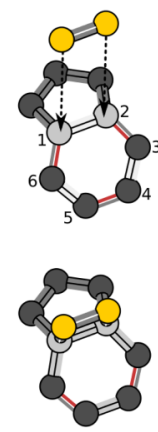

Bond Pristine a. after b. after $\begin{array}{llll}\mathrm{C} 1-\mathrm{C} 2 & 1.45 & 1.58 & 1.59\end{array}$ C1-C6 $1.4 \quad 1.46 \quad 1.49$ C5-C6 $1.45 \quad 1.39 \quad 1.39$

FIG. 2. A simplified model of the oxygen adsorption process and the rearrangement of the $\pi$ components of the double bonds in the case of [5,6]PCBM-2O (a) and [5,6]-PCBM-O ${ }_{2}$ (b). Single bonds are depicted in light grey, while double bonds are depicted as two parallel lines (dark grey and red). The black arrows mark the oxygen adsorption. The inset contains the relevant calculated bond lengths before and after oxygen adsorption. The shorter bonds (i.e., double bonds in character) are marked in bold in the table.

the epoxide. This appears to be in contrast to studies of $\mathrm{C}_{60} \mathrm{O}$ showing that the formation of the epoxide is more probable. $^{41-43}$ In our calculations, in fact, if the additional atom is not specifically placed across a 5-6 bond, the PCBM with oxygen relaxes to the epoxide, suggesting a larger energy barrier between the pristine molecule and the [5,6]-PCBM-O even if the overall binding energy is higher in the latter.

\section{2. $P C B M-20$}

The optimized geometries show similar trends as the PCBM with one oxygen case. More specifically, a 6-6 adsorption results in the breaking of the $\pi$ component of the double bond with the $\mathrm{sp}^{2}$ hybridized $\mathrm{C}$ atoms becoming $\mathrm{sp}^{3}$ hybridized. On the other hand, the oxygen adsorbed on a 5-6 site breaks the $\mathrm{C}-\mathrm{C}$ single bond, pushing the $\mathrm{C}$ atoms, which remain $\mathrm{sp}^{2}$ hybridized, as far apart as $2.18 \AA$ as seen in Table III.
The exception is the case of two separate oxygen atoms adsorbed on 5-6 sites from the same hexagon (Fig. 1 b3). In this case, the $\mathrm{O}$ chemisorption results in the breaking of the $\pi$ component of the adjacent double bonds instead of the single ones across the pentagon-hexagon at the adsorption site (Fig. 2(a)). The result is similar to the 6-6 case as the carbons involved in $\mathrm{C}-\mathrm{O}$ bonds become $\mathrm{sp}^{3}$ hybridized. This is possible because the two double bonded $\mathrm{C}$ atoms in the pristine molecule form single bonds with a different $\mathrm{O}$ atom in PCBM$2 \mathrm{O}$ at the same time. The process is illustrated in Figure 2(a), while the calculated bond lengths before and after oxygen adsorption can be found in the figure inset. The process will provide insight in the analysis of the O1s XPS and NEXAFS spectra to be discussed in the following sections.

\section{3. $\mathrm{PCBM}-\mathrm{O}_{2}$}

The optimized structure of the PCBM with an $\mathrm{O}_{2}$ molecule adsorbed on a 5-6 site is very similar to the [6,6]-PCBM-O geometry. The $\mathrm{O}-\mathrm{O}$ bond length is in both cases $1.5 \AA$, the $\mathrm{C}-\mathrm{O}$ is $1.45-1.46 \AA$ while the $\mathrm{C}-\mathrm{C}$ is $1.57 \AA$ in the case of the 6-6 adsorption site and $1.59 \AA$ in the case of the 5-6 one. In both cases therefore, the $\mathrm{sp}^{2}$ hybridized carbon atoms become $\mathrm{sp}^{3}$ hybridized. The explanation is straightforward in the 6-6 structure, since the formation of two new $\mathrm{C}-\mathrm{O}$ bonds leads to the scission of the $\pi$ component in the double bond with only a $\sigma$ bond remaining. In the case of the 5-6 structure, the $\mathrm{C}$ atoms are pushed away from each other, but the single bond at the pentagon-hexagon junction does not break. Instead, the adjacent double bonds are affected and rearrange as depicted in Figure 2(b). The 6-6 carbon atoms remain $\sigma$ bonded, while the $\pi$ components of the double bonds move to the empty 5-6 sites of the hexagon to which $\mathrm{O}_{2}$ is adsorbed.

In the cases when $\mathrm{O}_{2}$ is placed $4 \AA$ away from the $\mathrm{C}_{60}$ molecular moiety (Fig. $1 \mathrm{c} 3$ ), the structures are not optimized. A singlet and, respectively, a triplet $\mathrm{O}_{2}$ molecule with the $\mathrm{O}$ double bonded at $1.21 \AA$ were positioned away from the

TABLE IV. Peak positions for the calculated O1s XPS spectra. In the case of PCBM with two adsorbed atoms, when only 1 value is given, the two coincide. When two values are given, the first corresponds to the first adsorption site, while the second corresponds to the second adsorption site.

\begin{tabular}{llccc}
\hline \hline Adsorbate & Placement and site & $\mathrm{C}-\mathrm{O}-\mathrm{C}(\mathrm{eV})$ & $\mathrm{O}=\mathrm{C}(\mathrm{eV})$ & Extra oxygen(s) (eV) \\
\hline Pristine & & 533.41 & 531.50 & \\
\hline \multirow{5}{*}{$1 \mathrm{O}$ atom } & Opposite 6-6 & 533.43 & 531.52 & 532.30 \\
& Opposite 5-6 & 533.42 & 531.51 & 532.79 \\
& Middle 6-6 & 533.41 & 531.50 & 532.28 \\
& Tail 6-6 & 533.41 & 531.53 & 532.19 \\
& Opposite 6-6 6-6 & 533.45 & 531.55 & 532.39 \\
& Opposite 6-6 5-6 atoms & 533.44 & 531.54 & 532.40532 .83 \\
& Opposite 5-6 5-6 & 533.45 & 531.54 & 532.29 \\
& Middle 6-6 6-6 & 533.44 & 531.53 & 532.32532 .34 \\
& Middle 6-6 5-6 & 533.43 & 531.52 & 532.78532 .79 \\
& Middle 5-6 5-6 & 533.42 & 531.59 & 532.79532 .78 \\
& Opposite 6-6 & 533.46 & 531.55 & 532.12 \\
$\mathrm{O}_{2}$ molecule & Opposite 6-5 & 533.46 & 531.54 & 531.84 \\
& At 4 ${ }^{1} \mathrm{O}_{2}$ & 533.48 & 531.57 & 531.79531 .71 \\
& At 4 ${ }^{3} \mathrm{O}_{2}$ & 533.41 & 531.50 & $532.55_{\alpha} 532.27_{\beta}$ \\
\hline \hline
\end{tabular}


fullerene cage of the pristine PCBM previously optimized. Only a single-point energy calculation was performed and the XPS and NEXAFS spectra were determined for comparison with the two chemisorbed cases.

\section{Optimized geometries overview}

It is important to summarize the results of the preceding paragraphs and highlight a number of general conclusions which will become relevant for the analysis of the O1s XPS and NEXAFS spectra. First of all, the adsorption of an oxygen atom on a 6-6 site on the fullerene cage results in the scission of the $\pi$ component of the $\mathrm{C}-\mathrm{C}$ double bond. In other words, the $\mathrm{sp}^{2}$ hybridized $\mathrm{C}$ becomes $\mathrm{sp}^{3}$ hybridized when it binds to an $\mathrm{O}$ atom. In contrast, the chemisorption onto a 5-6 site determines the breaking of a $\mathrm{C}-\mathrm{C}$ single bond, meaning that the two atoms directly connected to the oxygen adsorbate remain $\mathrm{sp}^{2}$ hybridized carbons. This conclusion does not hold if two $\mathrm{O}$ atoms sit on 5-6 sites from the same hexagon. In this case, the $\mathrm{C}-\mathrm{C}$ single bond does not break, instead the $\pi$ components of the adjacent $\mathrm{C}-\mathrm{C}$ double bonds are the ones affected. In the case of molecular oxygen chemisorption, the 6-6 and 5-6 structures are very similar, since in both cases the $\mathrm{C}$ atoms bonded to oxygen become $\mathrm{sp}^{3}$ hybridized.

\section{B. 01s XPS}

\section{Pristine PCBM and PCBM-O}

The pristine PCBM O1s XPS spectrum is presented in Figure 3(a) in comparison with experimental data measured using a photon energy of $590 \mathrm{eV}$. The signal consists of two peaks denoted 1 and 2 in the figure. The first peak is centred around $533.41 \mathrm{eV}$ binding energy (Table IV) and is related to the ionization of the 1s state of the single bonded oxygen $(\mathrm{C}-\mathrm{O}-\mathrm{C})$ of the pristine PCBM side-chain (represented in blue in Fig. 1). The second peak arises at lower binding energy $(532.05 \mathrm{eV}$ in the experiment) and originates in the ionization of $1 \mathrm{~s}$ electrons from the double bonded oxygen $(\mathrm{O}=\mathrm{C})$ in the side-chain of the pristine molecule (represented in purple in Fig. 1). The calculated position of peak 2 is lower in energy (by $0.55 \mathrm{eV}$ ) as compared to the experiment (note that the calculation was shifted to match the experimental first peak by $5.2 \mathrm{eV}$ towards lower binding energy accounting for the work function), but nonetheless, the experiment-theory comparison is good and allows for clear peak assignment.

The XPS spectra of PCBM with one $\mathrm{O}$ atom are presented in Figures 3(b) and 3(c). The two epoxides having the $\mathrm{O}$ atom placed in the equatorial region of the $\mathrm{C}_{60}$ cage and, respectively, in the vicinity of side-chain show XPS signals which are very similar to the $[6,6]-\mathrm{PCBM}-\mathrm{O}$ with the oxygen opposite to the tail. These two spectra are included in the supplementary material, ${ }^{44}$ Fig. 1 . In all cases, the peak originating from the adsorbed oxygen is situated in between the two side-chain peaks. Moreover, there is a clear difference between the epoxide (Fig. 3(b)) and the open isomer (Fig. 3(c)). An oxygen adsorption on a 6-6 site results in the emergence of an additional XPS band closer in energy to the peak corresponding to the $\mathrm{O}$ double bond $(\mathrm{O}=\mathrm{C})$, thus enhancing peak 2 in the total spectrum. On the contrary, the oxygen atom chemisorbed on a 5-6 site contributes largely to the first peak in the total spectrum, since the additional peak is closer in energy to the $\mathrm{C}-\mathrm{O}-\mathrm{C}$ band at higher binding energy.

\section{PCBM-2O}

The O1s XPS spectra of PCBM having two O atoms attached to the fullerene cage are similar in trends to the PCBM-O case. The atoms adsorbed on a 6-6 site give rise to lower binding energy peaks, while the 5-6 adsorbed $\mathrm{O}$ contribute to the higher binding energy region. More specifically, when both atoms chemisorb on a 6-6 site (Fig. 4(a)), the total spectrum presents a largely enhanced 2nd peak. In the case of a combination of both 6-6 and 5-6 adsorption (Fig. 4(b)), the result is a total spectrum with less well resolved peaks and a relatively more enhanced 1 st peak. The reason for this enhancement is the fact that the 5-6 band is closer in energy to the $\mathrm{C}-\mathrm{O}-\mathrm{C}$ than is the 6-6 band to the $\mathrm{O}=\mathrm{C}$.

When both oxygen atoms are adsorbed on a 5-6 site, two distinct cases were identified. First of all, when the two atoms are adsorbed in different hexagons of the fullerene cage (Fig. 4(d)), the result is similar to the PCBM-O case. The two extra oxygen atoms both contribute to the higher binding
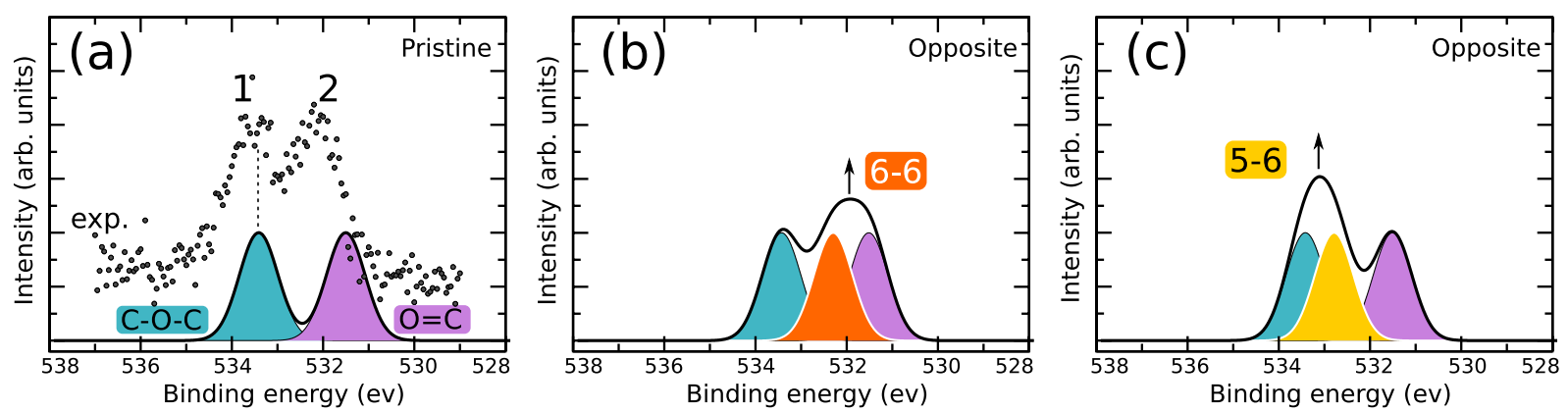

FIG. 3. O1s XPS calculated spectra of pristine PCBM (a) and two configurations of PCBM with one oxygen adsorbed on the fullerene cage: opposite of the side-chain in a 6-6 site (b) and opposite of the side-chain in a 5-6 site (c). The experimental spectrum of PCBM is shown in comparison with the calculated spectrum of the pristine molecule (a). The arrows mark the peak being enhanced due to the presence of the additional $\mathrm{O}$ atom. The band originating from the 5-6 oxygen is depicted in yellow (c), while the band originating from the 6-6 oxygen is marked in orange (b). The peaks related to the side-chain oxygen atoms are blue and purple, respectively, consistent with the colouring used in Fig. 1. 

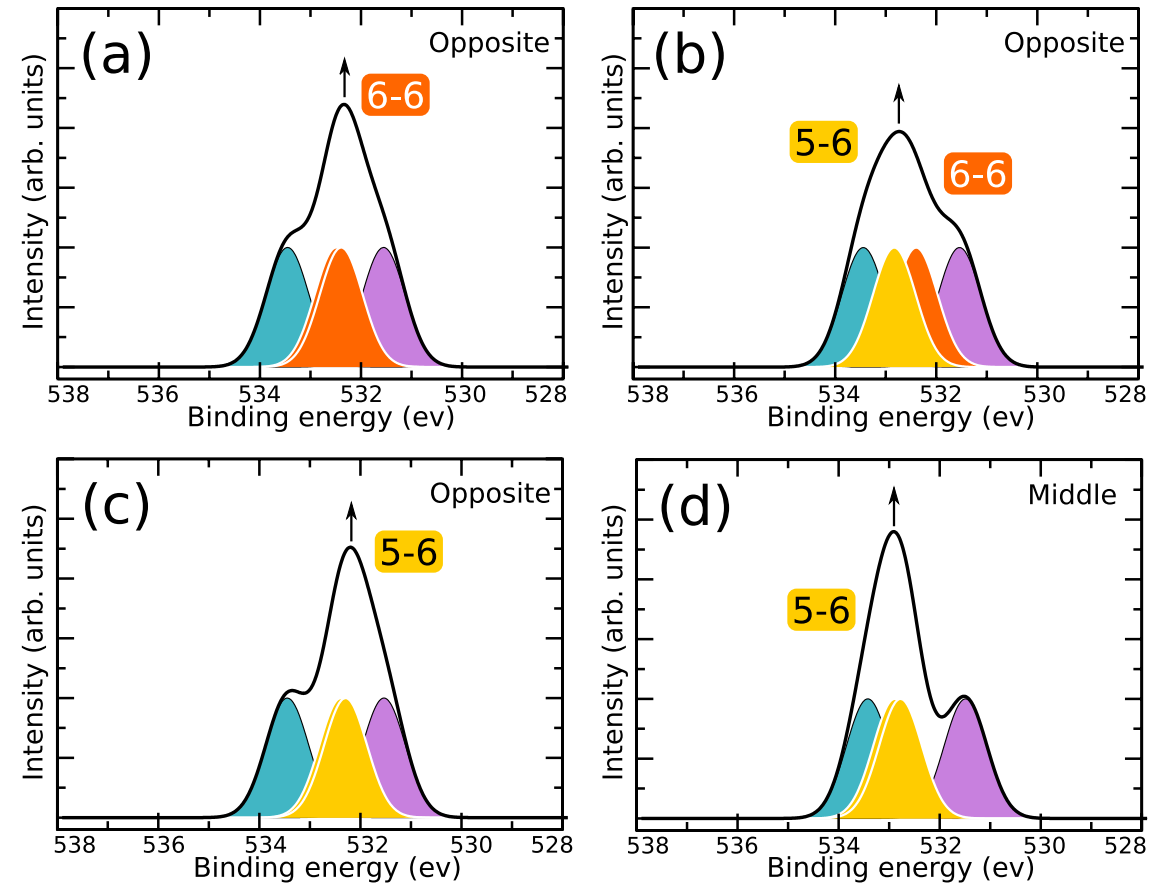

FIG. 4. O1s XPS calculated spectra of several configurations of PCBM with two $\mathrm{O}$ atoms adsorbed on the fullerene cage: opposite of the side-chain with both atoms on 6-6 sites (a), opposite of the side-chain, one $\mathrm{O}$ on a 6-6 site, one on a 5-6 site (b), opposite to the sidechain, both atoms on 5-6 sites from the same hexagon (c), and in the equatorial region, both atoms on 5-6 sites (d). energy side of the spectrum, resulting in a total signal with a largely enhanced peak 1 .

In contrast, if the $\mathrm{O}$ atoms are located on 5-6 sites from the same hexagon (Fig. 4(c)), the total signal is very similar to the epoxide isomer cases (adsorption on a 6-6 site). This can be explained by the fact that the local geometry of the [5,6]-PCBM-2O isomer with the $2 \mathrm{O}$ in the same hexagon is very similar to the PCBM-O with the adsorbate on a 6-6 site. The $\mathrm{O}$ chemisorption does not break the $\mathrm{C}-\mathrm{C}$ single bond at the adsorption site but affects the adjacent $\pi$ bonds instead.

\section{3. $\mathrm{PCBM}-\mathrm{O}_{2}$}

For the $\mathrm{PCBM}-\mathrm{O}_{2}$ structures, the chemisorbed oxygen cases (Figs. 5(a) and 5(b)) give rise to XPS signals, which are very similar to the singlet $\mathrm{O}_{2}$ calculated spectrum (supplementary material, ${ }^{44}$ Fig. 3). In all these three cases, the additional oxygen signal contributes largely to peak 2 . The total spectrum consists therefore of two well resolved peaks, the lower binding energy one being greatly enhanced. The fact that there is no clear difference between a 5-6 and a 6-6 adsorption can be explained by the similarity in their optimized geometries. During $\mathrm{O}_{2}$ chemisorption on a 5-6 site, the single bond across the pentagon and hexagon does not break. The $\mathrm{C}$ atoms at the adsorption site remain $\sigma$ bonded, while the $\pi$ bonds rearrange in the hexagonal ring. On the other hand, the triplet oxygen placed $4 \AA$ from the cage gives rise to a slightly asymmetric total spectrum, more intense in the peak 2 region but with low resolution of peaks 1 and 2 (Fig. 5(c)). The reason for this is that the calculated IP values differ in the case of the spin up electrons (majority - $\alpha$ ) and spin down electrons (minority - $\beta$ ) by $0.22 \mathrm{eV}$. Ionizing from the spin up gives rise to a peak located at higher binding energies closer in energy to the $\mathrm{C}-\mathrm{O}-\mathrm{C}$ band, while an ionization of an $\mathrm{O} 1 \mathrm{~s}$ spin down electron results in the emergence of an additional peak slightly closer to the $\mathrm{O}=\mathrm{C}$ band. This difference in IPs arises from the difference in the exchange interactions involving the $\alpha$ and $\beta$ electrons of the open-shell $\mathrm{O}_{2}$ molecule. The removal of a spin up electron leads to the formation of a doublet ionic state (having a $1 / 2$ total spin), while the removal of a spin down electron results in a quadruplet final state (having a $3 / 2$ total spin). ${ }^{39}$
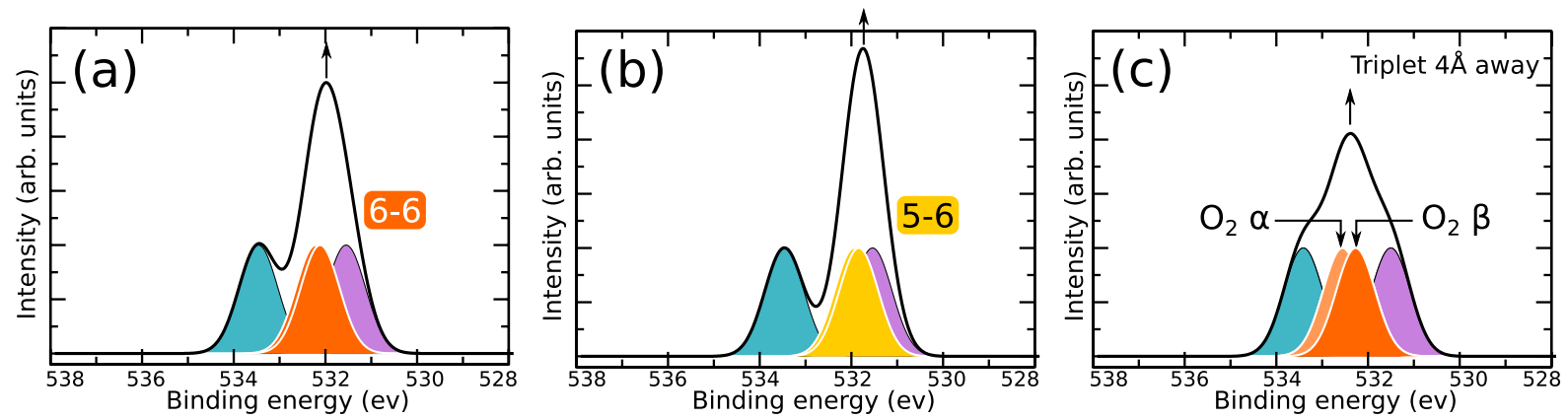

FIG. 5. O1s XPS calculated spectra of three configurations of PCBM with molecular oxygen adsorbed to the cage opposite of the side-chain: (a) the $\mathrm{O}_{2}$ molecule chemisorbs on a 6-6 site, (b) the chemisorption takes place on a 5-6 site, and (c) the $\mathrm{O}_{2}$ is placed at $4 \AA$ away from the $\mathrm{C}_{60}$ cage. 


\section{XPS results overview}

In brief, by comparing the three sets of results (PCBM-O, PCBM-2O, and PCBM-O ${ }_{2}$ ), it is possible to draw a number of general conclusions. First of all, the adsorption of either an oxygen atom or a molecule results in the emergence of an additional peak situated in between the two O1s peaks of the pristine PCBM.

Second, in all the cases, where the $\mathrm{C}-\mathrm{C}$ single bond at the 5-6 adsorption site breaks, the additional O1s band contributes to the higher binding energy peak in the total spectrum. On the other hand, when only $\pi \mathrm{C}-\mathrm{C}$ bonds are affected, the extra oxygen contributes to the lower binding energy region. The O1s XPS can thus be used to reveal if any $\mathrm{C}-\mathrm{C}$ single bond breaks during oxygen chemisorption on the fullerene cage.

The adsorption of molecular oxygen in the singlet state is related to a strong enhancement of the well-resolved peak 2 in the total spectrum. The triplet (ground state) oxygen determines instead a slightly asymmetric total spectrum, with the second band $(\mathrm{O}=\mathrm{C})$ region more intense and a low resolution between the two bands.

Even though the O1s XPS can offer valuable insight into the breaking of cage carbon single bonds, it is by itself not enough to uniquely point towards the type of adsorption site or the nature of the adsorbate. An additional spectroscopy is needed for gaining this extra information. We have therefore calculated the theoretical NEXAFS spectra since this technique can probe the energies of the unoccupied molecular orbitals, and in addition, is more sensitive to the chemical environment around the core excited atom.

\section{O1s NEXAFS}

\section{Pristine PCBM and PCBM-O}

The calculated NEXAFS spectrum of the pristine molecule is shown in Figure 6(a), alongside the experimental spectrum of the unexposed PCBM film. The measured signal presents four bands denoted with numbers (1-4) in the figure. Two separate regions are identified by $\pi^{*}$ (the 1 st peak followed by peaks 2 and 3 ) and $\sigma^{*}$ (peak 4 and above). ${ }^{39}$ The calculated total spectrum compares well to the experiment (note that a $0.6 \mathrm{eV}$ shift towards lower photon energies was performed to align the calculated spectrum of the pristine molecule to the experimental first peak; this shift is related to relativistic effects not accounted for by the calculation ${ }^{25}$ ) and the analysis of the separate contributions $(\mathrm{O}=\mathrm{C}$ and $\mathrm{C}-\mathrm{O}-\mathrm{C})$ allows for clear peak assignment. The first experimental band, centred around $531.0 \mathrm{eV}$, originates exclusively in the double bonded oxygen of the side-chain (in purple, Figs. 1 and 6(a)), while peaks $2(533.7 \mathrm{eV}), 3(535.6 \mathrm{eV})$, and $4(538.9 \mathrm{eV})$ are mainly due to excitations of $1 \mathrm{~s}$ electrons from the single bonded oxygen of the PCBM side chain (in blue, Figs. 1 and 6(a)).

The calculated NEXAFS spectra of PCBM with one O atom adsorbed on the cage in positions opposite to the side chain are depicted in Figures 6(b) and 6(c). The other two 6-6 positions on the cage are presented in the supplementary material $^{44}$ and give rise to NEXAFS spectra very similar to the [6,6]-PCBM-O isomer (Fig. 6(b)). The individual contribution of the additional atom is marked in orange (for a 6-6 adsorption) or yellow (for a 5-6 adsorption). Irrespective of the placement on cage, chemisorption on a 6-6 site (Fig. 6(b)) results in the emergence of a shoulder to peak 1 (denoted $\mathrm{S}$ in the figure), approximately $1 \mathrm{eV}$ higher in energy. In addition, another common feature to these three cases is the enhancement of peak 3 . From being lower in intensity in the pristine molecule, it becomes as intense as peak 4 as a result of 6-6 adsorption. On the other hand, the 5-6 structure (Fig. 6(c)) almost completely lacks shoulder $\mathrm{S}$ and has a largely enhanced peak 4 with essentially no change in the intensity of peaks 2 and 3 .

It is important to note that in the calculated NEXAFS spectra of all the four PCBM-O structures, the contribution of the additional oxygen atom is very similar in shape to the $\mathrm{C}-\mathrm{O}-\mathrm{C}$ contribution. More specifically, it lacks the strong $\pi^{*}$ peak, having instead several lower intensity bands in the region of peaks 2 and 3 (6-6 adsorption) or in the $\sigma^{*}$ region (5-6 adsorption). This is consistent with the fact that the additional $\mathrm{O}$, bridging between carbon atoms of the cage, is involved in two single bonds with these atoms just as the side chain single bonded oxygen forms bonds with 2 carbons (C-O-C).

\section{2. $P C B M-20$}

As it was the case with the O1s XPS, the trends observed in the NEXAFS of PCBM-2O (Fig. 7) are similar to the ones of PCBM-O. The atoms adsorbed on 6-6 site develop the S
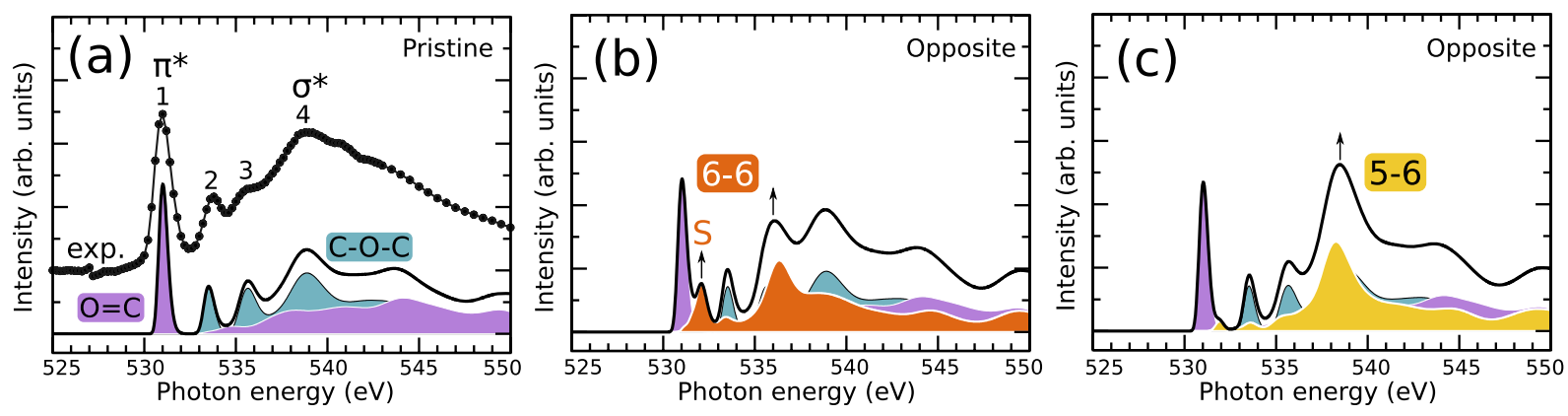

FIG. 6. Calculated O1s NEXAFS spectra of pristine PCBM (a) and two configurations of PCBM with one oxygen adsorbed on the fullerene cage, opposite of the side-chain: on a 6-6 site (b), and on a 5-6 site (c). The experimental TEY NEXAFS spectrum of PCBM is shown in comparison with the calculated signal of the pristine molecule (a). The arrows mark the emerging additional peaks due to the adsorbed $\mathrm{O}$ atom. 

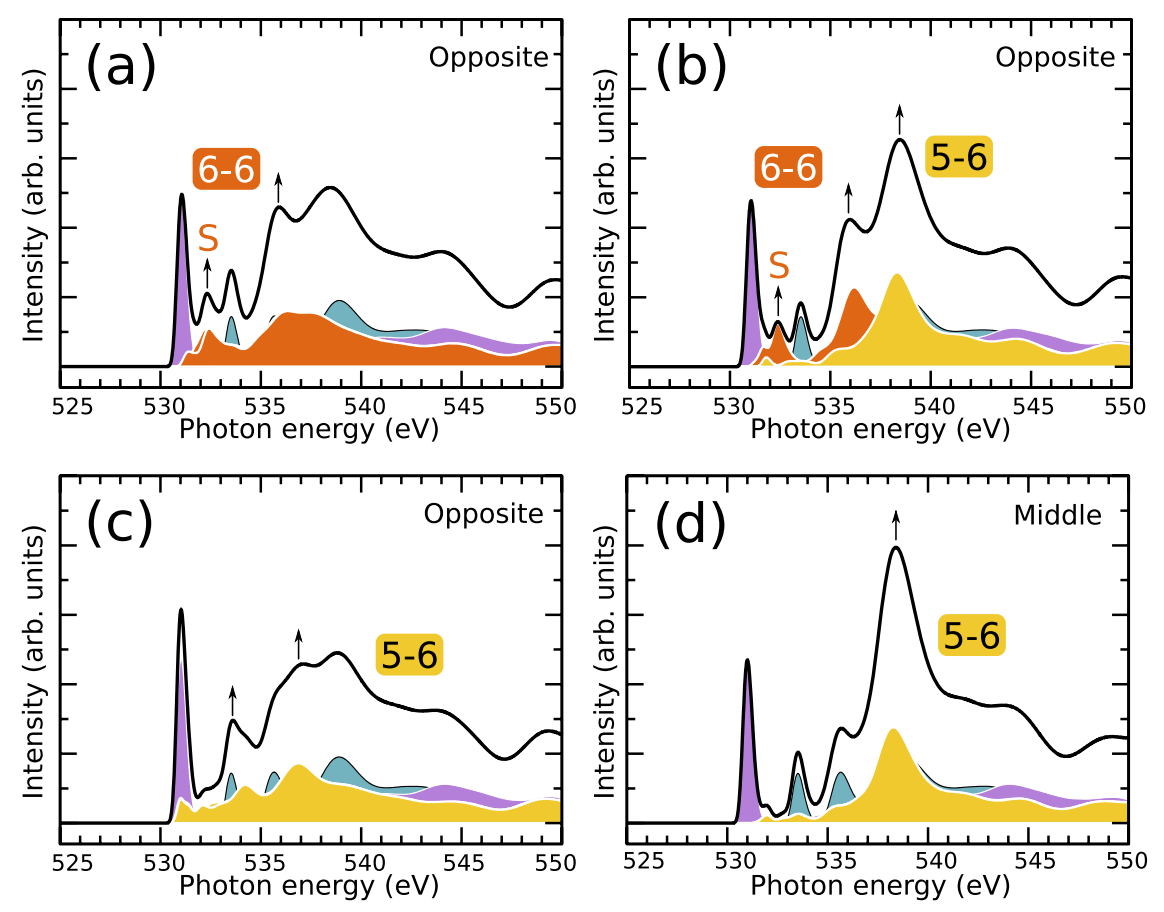

FIG. 7. Calculated O1s NEXAFS spectra of several configurations of PCBM with two $\mathrm{O}$ atoms adsorbed on the fullerene cage: opposite of the sidechain, both atoms on 6-6 sites (a), opposite of the side-chain, one $\mathrm{O}$ on a 6-6 site, the other on a 5-6 site (b), opposite to the side-chain, both atoms on 5-6 sites from the same hexagon (c), and in the equatorial region, both atoms on 5-6 sites (d). shoulder and contribute to peak 3, while the 5-6 adsorbed atoms have a strong band in the $\sigma^{*}$ region, contributing in the majority of cases to peak 4.

In detail, the adsorption of both $\mathrm{O}$ atoms on 6-6 sites (Fig. 7(a)) determines the emergence of shoulder $\mathrm{S}$ in the vicinity of the 1 st peak, $1 \mathrm{eV}$ higher in energy. Moreover, peak 3 increases in intensity and becomes comparable to peak 4.

The adsorption of one atom on a 6-6 site and the other on a 5-6 site (Fig. 7(b)) results in a combination of the two effects described in the PCBM-O paragraph: the emergence of the S-shoulder and enhancement of peak 3 on the one hand, and the strong growth in the intensity of peak 4 on the other hand. The analysis of the separate contributions from the additional oxygen atoms reveals that the 6-6 $\mathrm{O}$ is the origin of the shoulder and of the peak 3 enhancement, while the 5-6 O is responsible for the intensity growth of peak 4 (Fig. 7(b)).

Finally, when both atoms adsorb on 5-6 sites (Figs. 7(c) and $7(\mathrm{~d})$ ), two different cases can be identified. The structure with the two atoms located in distinct hexagons highly resembles the corresponding PCBM-O case, in other words, the intensity of peak 4 grows significantly. On the other hand, when the oxygen atoms are adsorbed in the same hexagon (Fig. 7(c)), there is no increase in peak 4. Instead, a new feature emerges in between peaks 3 and 4, accompanied by a slight increase in the 2nd peak's intensity. Important to note is the fact that both cases described above almost completely lack shoulder $\mathrm{S}$ (which thus becomes a fingerprint of the 6-6 adsorption) in the total spectrum.

\section{3. $\mathrm{PCBM}-\mathrm{O}_{2}$}

All the four structures with molecular $\mathrm{O}_{2}$ adsorbed to the fullerene cage are very similar to each other (Fig. 8 and supplementary material ${ }^{44}$ Fig. 6). The additional oxygen is responsible for the emergence of a very strong peak at slightly lower photon energy than the $\mathrm{O}=\mathrm{C}$ band. The $\sigma^{*}$ region becomes quite low in intensity when compared to the new feature. This is an indication that the LUMO in the presence of the half core hole is shifted to higher binding energies and becomes localized at the adsorption site during core excitation (supplementary material, ${ }^{44}$ Fig. 7).

The PCBM-O ${ }_{2}$ structure having the molecule chemisorbed on a 6-6 site (Fig. 8(a)), in addition to the features already described, presents a shoulder at the high energy side of the $\pi^{*}$ peak $(0.6 \mathrm{eV}$ higher) similar to the other 6-6 structures discussed in the previous paragraphs. This shoulder is nonetheless closer in energy to the $\pi^{*}$ than it is in these other cases.

When $\mathrm{O}_{2}$ is placed in the vicinity of the cage (Fig. 8(c)), a strong peak develops $1 \mathrm{eV}$ before the $\pi^{*}$. The new feature is more intense and located at lower photon energy (by $0.5 \mathrm{eV}$ ) as compared to the same band from the chemisorbed cases. Nevertheless, this highly intense peak is characteristic to all the four $\mathrm{O}_{2}$ structures and is in this case a fingerprint of the oxygen-oxygen bond.

In the case of the triplet $\mathrm{O}_{2}$, excitations from the $\alpha$ (majority) and $\beta$ (minority) electrons give different contributions to the total signal. It is in fact the spin down $(\beta)$ electrons which are exclusively responsible for the strong low photon energy peak, while the spin-up electrons contribute only to the $\sigma^{*}$ region. This is because the transition of a spin-up electron to the singly occupied molecular orbital in the triplet $\mathrm{O}_{2}$ valence band is not allowed by the Pauli exclusion principle and the dipole selection rules ${ }^{39}$ and only the spin-down electrons can undergo this excitation (Fig. 8(d)).

\section{NEXAFS results overview}

The comparison of the three distinct oxygen adsorption structures (PCBM-O, PCBM-2O, and $\mathrm{PCBM}-\mathrm{O}_{2}$ ) reveals a number of general trends. First, in all cases where oxygen 

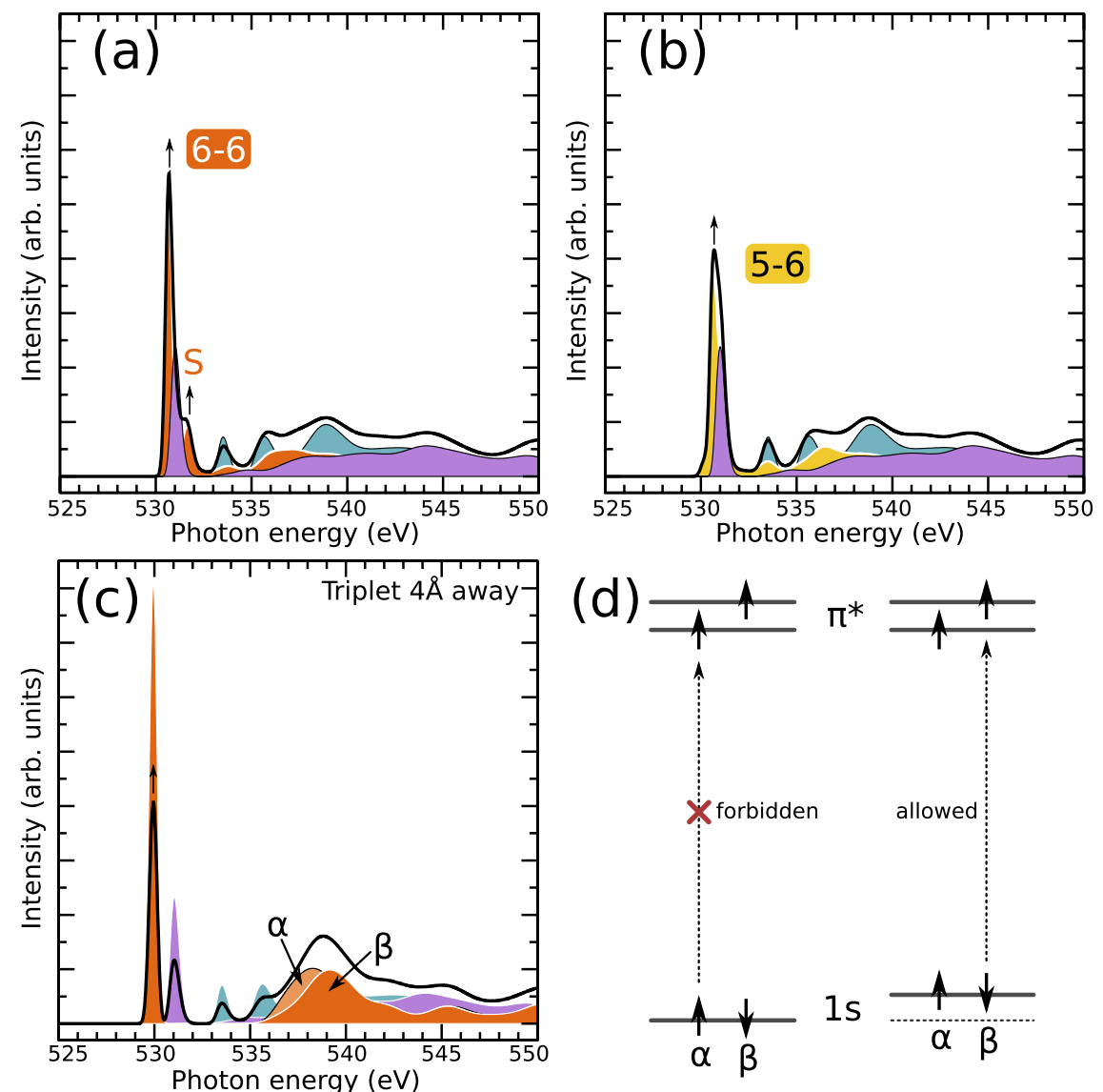

FIG. 8. Calculated O1s NEXAFS spectra of three configurations of PCBM with molecular oxygen adsorbed to the cage opposite of the side-chain: the $\mathrm{O}_{2}$ molecule chemisorbs on a 6-6 site (a), the chemisorption takes place on a 56 site (b), and the triplet $\mathrm{O}_{2}$ is placed at $4 \AA$ away from the $\mathrm{C}_{60}$ cage (c). A schematic representation of the electronic levels of an isolated $\mathrm{O}_{2}$ molecule in the triple state ${ }^{39}$ is represented alongside (d).

is adsorbed onto a 6-6 site, a new shoulder emerges at approximately $1 \mathrm{eV}$ higher photon energies than the $\pi^{*}$ NEXAFS peak (the value is $0.6 \mathrm{eV}$ in the case of $[6,6]-$ $\mathrm{PCBM}-\mathrm{O}_{2}$ ). This shoulder could be used as a fingerprint of the 6-6 adsorption.

Second, when oxygen is adsorbed on a 5-6 site, the shoulder is absent and an increase in intensity in the $\sigma^{*}$ region, especially peak 4, is observed instead. Enhancement of the $\sigma^{*}$ could be used therefore as an indication of 5-6 adsorption of atomic oxygen.

The presence of molecular oxygen, either chemisorbed on the cage or placed in its vicinity, results in the emergence of a highly intense peak situated at lower photon energy than the $\pi^{*}$, the total spectrum being in addition characterized by a low intensity $\sigma^{*}$ region.

\section{DISCUSSION}

The spectroscopic signatures in O1s XPS and NEXAFS can be used for fingerprinting the type of chemical interaction when the exclusive presence of oxygen is known or controlled. To be more specific, we have shown that the occurrence of oxygen, either chemisorbed or present in the vicinity of the cage is related to an asymmetry between peaks $\mathrm{O}=\mathrm{C}$ and $\mathrm{C}-\mathrm{O}-\mathrm{C}$ in the XPS (note that our study only includes pure oxygen and no other molecular groups containing $\mathrm{O}$ atoms). The molecular oxygen adsorption is clearly indicated by the emergence in the NEXAFS spectrum of a strong peak situated at lower photon energy compared to the $\pi^{*}$ band and by the low intensity of the $\sigma^{*}$ region, while an adsorption on a 6-6 site results in the emergence of a higher photon energy shoulder to the $\pi^{*}$. We have demonstrated as well that NEXAFS spectroscopy can be used to identify 5-6 adsorbed oxygen atoms since this type of adsorption leads to strong enhancement of the $\sigma^{*}$ region, in particular, peak 4. Moreover, a highly intense peak $2(\mathrm{C}-\mathrm{O}-\mathrm{C})$ in the O1s XPS indicates that a $\mathrm{C}-\mathrm{C}$ single bond has been broken at the adsorption site.

The formation of PCBM-O or PCBM-O $\mathrm{P}_{2}$ can compromise the performance of OPV devices since the interaction with each oxygen atom is responsible for a slight increase in the LUMO binding energy. ${ }^{9}$ The LUMO of the electron acceptor is directly linked to the maximum open circuit voltage $\left(\mathrm{V}_{\mathrm{oc}}\right)$ that can be obtained by the solar cell and a shift downwards in the LUMO position means a decrease in $\mathrm{V}_{\mathrm{oc}}{ }^{45}$ In addition, the modification of the LUMO could also mean a stronger localization and the creation of traps favourable to electronhole recombination ${ }^{15}$ leading to losses in current for the OPV device. It is therefore crucial to determine whether oxygen adsorbs to PCBM before or during device functioning and the combination of O1s XPS and NEXAFS spectroscopies provides a reliable method to do so.

\section{CONCLUSIONS}

In summary, we have analysed the O1s XPS and NEXAFS spectra of pristine PCBM and of several configurations of PCBM with one oxygen atom, two oxygen atoms, and, respectively, one oxygen molecule adsorbed to the $\mathrm{C}_{60}$ molecular 
moiety. Two different possible sites for oxygen adsorption were studied for each structure: $\mathrm{O}$ adsorption onto 6-6 sites and onto 5-6 sites. Our results show that the combination of O1s XPS and NEXAFS can give important insight into not only the nature of the adsorbate (atomic or molecular oxygen) but also into the type of adsorption site and the nature of the bonds that break in the fullerene cage as a result of $\mathrm{O}$ chemisorption.

\section{ACKNOWLEDGMENTS}

We acknowledge the Swedish Research Council (VR), the KAW Foundation, the Göran Gustafsson Foundation for Research in Natural Sciences and Medicine, and the Swedish National Infrastructure for Computing (SNIC). Support from eSSENCE and STandUP are also acknowledged. We thank the staff at Maxlab beamline D1011 for technical support and advice.

${ }^{1}$ N. Espinosa, R. García-Valverde, A. Urbina, and F. C. Krebs, Sol. Energy Mater. Sol. Cells 95, 1293-1302 (2011).

${ }^{2}$ M. Jørgensen, J. E. Carlé, R. R. Søndergaard, M. Lauritzen, N. A. DagnæsHansen, S. L. Byskov, T. R. Andersen, T. T. Larsen-Olsen, A. P. Böttiger, B. Andreasen, L. Fu, L. Zuo, Y. Liu, E. Bundgaard, X. Zhan, H. Chen, and F. C. Krebs, Sol. Energy Mater. Sol. Cells 119, 84-93 (2013).

${ }^{3}$ Z. He, C. Zhong, X. Huang, W.-Y. Wong, H. Wu, L. Chen, S. Su, and Y. Cao, Adv. Mater. 23, 4636-4643 (2011).

${ }^{4}$ N. Espinosa, M. Hosel, D. Angmo, and F. C. Krebs, Energy Environ. Sci. 5, 5117-5132 (2012).

${ }^{5}$ S. Günes, H. Neugebauer, and N. S. Sariciftci, Chem. Rev. 107, 1324-1338 (2007).

${ }^{6}$ Y. He and Y. Li, Phys. Chem. Chem. Phys. 13, 1970-1983 (2011).

${ }^{7}$ M. Jørgensen, K. Norrman, and F. C. Krebs, "Degradation and stability of polymer and organic solar cells," Sol. Energy Mater. Sol. Cells 92, 686-714 (2008).

${ }^{8}$ S. Chambon, A. Rivaton, J.-L. Gardette, and M. Firon, Sol. Energy Mater. Sol. Cells 91, 394-398 (2007).

${ }^{9}$ M. O. Reese, A. M. Nardes, B. L. Rupert, R. E. Larsen, D. C. Olson, M. T. Lloyd, S. E. Shaheen, D. S. Ginley, G. Rumbles, and N. Kopidakis, Adv. Funct. Mater. 20, 3476 (2010).

${ }^{10}$ E. A. Katz, D. Faiman, B. Mishori, Y. Shapira, A. I. Shames, S. Shtutina, and S. Goren, J. Appl. Phys. 84, 3333-3337 (1998).

${ }^{11}$ B. W. Larson, J. B. Whitaker, A. A. Popov, N. Kopidakis, G. Rumbles, O. V. Boltalina, and S. H. Strauss, Chem. Mater. 26, 2361-2367 (2014).

${ }^{12}$ A. Distler, T. Sauermann, H.-J. Egelhaaf, S. Rodman, D. Waller, K.-S. Cheon, M. Lee, and D. M. Guldi, Adv. Energy Mater. 4, 1300693 (2014).

${ }^{13}$ M. Jørgensen, K. Norrman, S. A. Gevorgyan, T. Tromholt, B. Andreasen, and F. C. Krebs, Adv. Mater. 24, 580-612 (2012).

${ }^{14}$ Q. Bao, X. Liu, S. Braun, and M. Fahlman, Adv. Energy Mater. 4, 1-6 (2014).

${ }^{15} \mathrm{G}$. Volonakis, L. Tsetseris, and S. Logothetidis, Org. Electron. 14, 1242-1248 (2013).

${ }^{16}$ A. D. Becke, J. Chem. Phys. 98, 5648 (1993).

${ }^{17}$ V. A. Rassolov, J. A. Pople, M. A. Ratner, and T. L. Windus, J. Chem. Phys. 109, 1223 (1998)

${ }^{18}$ M. J. Frisch, G. W. Trucks, H. B. Schlegel, G. E. Scuseria, M. A. Robb, J. R. Cheeseman, G. Scalmani, V. Barone, B. Mennucci, G. A. Petersson, H.
Nakatsuji, M. Caricato, X. Li, H. P. Hratchian, A. F. Izmaylov, J. Bloino, G. Zheng, J. L. Sonnenberg, M. Hada, M. Ehara, K. Toyota, R. Fukuda, J. Hasegawa, M. Ishida, T. Nakajima, Y. Honda, O. Kitao, H. Nakai, T. Vreven, J. J. A. Montgomery, J. E. Peralta, F. Ogliaro, M. Bearpark, J. J. Heyd, E. Brothers, K. N. Kudin, V. N. Staroverov, R. Kobayashi, J. Normand, K. Raghavachari, A. Rendell, J. C. Burant, S. S. Iyengar, J. Tomasi, M. Cossi, N. Rega, J. M. Millam, M. Klene, J. E. Knox, J. B. Cross, V. Bakken, C. Adamo, J. Jaramillo, R. Gomperts, R. E. Stratmann, O. Yazyev, A. J. Austin, R. Cammi, C. Pomelli, J. W. Ochterski, R. L. Martin, K. Morokuma, V. G. Zakrzewski, G. A. Voth, P. Salvador, J. J. Dannenberg, S. Dapprich, A. D. Daniels, Ö. Farkas, J. B. Foresman, J. V. Ortiz, J. Cioslowski, and D. J. Fox, Gaussian 09, Revision C.01, Gaussian, Inc., Wallingford, CT, 2009.

${ }^{19}$ K. Hermann, L. G. M. Pettersson, M. E. Casida, C. Daul, A. Goursot, A. Koester, E. Proynov, A. St-Amant, and D. R. Salahub, StoBe-deMon version 3.0, 2007.

${ }^{20}$ A. D. Becke, Phys. Rev. A 38, 3098 (1988).

${ }^{21}$ J. P. Perdew, Phys. Rev. B 33, 8822 (1986).

${ }^{22}$ A. Nilsson and L. G. M. Pettersson, Surf. Sci. Rep. 55, 49-167 (2004).

${ }^{23}$ J. C. Slater and K. H. Johnson, Phys. Rev. B 5, 844 (1972).

${ }^{24}$ I. E. Brumboiu, A. Anselmo, B. Brena, A. Dzwilewski, K. Svensson, and E. Moons, Chem. Phys. Lett. 568-569, 130-134 (2013).

${ }^{25}$ L. Triguero, O. Plashkevych, L. Pettersson, and H. Ågren, J. Electron Spectrosc. Relat. Phenom. 104, 195-207 (1999).

${ }^{26}$ M. Dresselhaus, G. Dresselhaus, and P. Eklund, in Science of Fullerenes and Carbon Nanotubes, edited by M. D. D. Eklund (Academic Press, San Diego, 1996), pp. 292-328.

27J. M. Schulman, R. L. Disch, M. A. Miller, and R. C. Peck, Chem. Phys. Lett. 141, 45-48 (1987).

${ }^{28}$ H. P. Lüthi and J. Almlöf, Chem. Phys. Lett. 135, 357-360 (1987).

${ }^{29}$ G. E. Scuseria, Chem. Phys. Lett. 176, 423-427 (1991).

${ }^{30}$ M. Häser, J. Almlöf, and G. E. Scuseria, Chem. Phys. Lett. 181, 497-500 (1991).

${ }^{31}$ C. S. Yannoni, P. P. Bernier, D. S. Bethune, G. Meijer, and J. R. Salem, J. Am. Chem. Soc. 113, 3190-3192 (1991).

${ }^{32}$ I. F. D. William, M. I. Richard, C. M. Judy, K. Prassides, T. Dennis, S. John, P. H. Jonathan, W. K. Harold, R. Taylor, and R. M. W. David, Nature 353, 147-149 (1991).

${ }^{33}$ K. Hedberg, L. Hedberg, D. Bethune, C. Brown, H. Dorn, R. Johnsson, and M. de Vries, Science 254, 410 (1991).

${ }^{34}$ F. Diederich and C. Thilgen, Science 271, 317 (1996).

${ }^{35}$ Fullerenes and Related Structures, edited by A. Hirsch, Topics in Current Chemistry (Springer, Berlin, Heidelberg, 1999), Vol. 199, pp. 1-65.

${ }^{36}$ W. Kern and D. Puotinen, RCA Rev. 31, 187 (1970).

${ }^{37}$ W. Kern, J. Electrochem. Soc. 137, 1887 (1990).

${ }^{38}$ G. Kissinger and W. Kissinger, Phys. Status Solidi A 123, 185-192 (1991).

${ }^{39}$ J. Stöhr, NEXAFS Spectroscopy, Springer Series in Surface Sciences (Springer-Verlag, Berlin, 1992).

${ }^{40}$ B. Watts, L. Thomsen, and P. Dastoor, J. Electron Spectrosc. Relat. Phenom. 151, 105-120 (2006).

${ }^{41}$ W. Y. Sohn, T. W. Kim, and J. S. Lee, J. Phys. Chem. A 114, 1939-1943 (2010).

${ }^{42}$ R. B. Weisman, D. Heymann, and S. M. Bachilo, J. Am. Chem. Soc. 123, 9720-9721 (2001).

${ }^{43}$ D. Tsyboulski, D. Heymann, S. M. Bachilo, L. B. Alemany, and R. B. Weisman, J. Am. Chem. Soc. 126, 7350-7358 (2004).

${ }^{44}$ See supplementary material at http://dx.doi.org/10.1063/1.4907012 for the calculated O1s XPS and NEXAFS spectra of five other PCBM with oxygen configurations and the LUMO of $[6,6]-\mathrm{PCBM}-\mathrm{O}_{2}$.

${ }^{45}$ A. Gadisa, M. Svensson, M. R. Andersson, and O. Inganäs, Appl. Phys. Lett. 84, 1609-1611 (2004). 